\title{
Erratum
}

\section{INDEL Length and Haplotypes in the $\beta$-Synuclein Gene: A Key to Differentiate Dementia with Lewy Bodies?}

Ana Gámez-Valero, Julia Canet-Pons, Aintzane Urbizu, Ana Anillo, Cristina Santos, Aurelioa Ariza \& Katrin Beyer

[Journal of Alzheimer's Disease, 65(1) 2018, 207-219, DOI 10.3233/JAD-180074]

https://content.iospress.com/articles/journal-of-alzheimers-disease/jad180074

Pre-press 12 May 2021

On page 217, in the Acknowledgements section the following funding statement should be added:

"This study has been funded by Instituto de Salud Carlos III through the project "PI15/00216" (Co-funded by European Regional Development Fund/European Social Fund "A way to make Europe"/"Investing in your future"” 